1 How to improve foraging efficiency for restocking measures of juvenile Baltic sturgeon

2 (Acipenser oxyrinchus)

3

4 Maria Cámara-Ruiz ${ }^{1}$, Carlos Espirito Santo ${ }^{1}$, Joern Gessner ${ }^{1}$, Sven Wuertz $^{1}$

5

6

$7 \quad{ }^{1}$ Leibniz Institute of Freshwater Ecology and Inland Fisheries, Berlin, Germany

8

9

*Corresponding author:

M. Cámara-Ruiz

Leibniz Institute of Freshwater Ecology and Inland Fisheries, Berlin, Germany

Tel: +49 (0)3064181614

Email address: ruiz@igb-berlin.de 
ABSTRACT

Atlantic sturgeon (Acipenser oxyrinchus), also known as Baltic sturgeon, is considered missing or extinct in German waters. Current conservation efforts focus on re-stocking activities, but classical hatchery rearing may reduce the fitness of the respective juveniles. In this study, we evaluated if foraging efficiency can be improved by short term training. Over a period of $14 \mathrm{~d}$, we kept individuals of the training group in a raceway and fed them chironomids buried in a small sand spot to stimulate benthic feeding behavior while fish of the control group were fed in tanks without substrate. Thereafter, each fish was transferred to a raceway entirely covered with sand. For feeding, chironomids were randomly buried in the sand. During the first 7 days, trained fish recovered the feed significantly faster than untrained fish of the control group. Gene expression revealed an up-regulation in neurodl in all brain regions after $14 \mathrm{~d}$ of training. Thus, this study suggests that foraging efficiency can be improved through short-time training thus improve fitness upon restocking into the wild.

\section{Table of Abbreviations}

d- days

TL- total length

Key words: Acipenser oxyrinchus, fitness, foraging, conservation, neuroD1, pcna, bdnf, restocking 


\section{Introduction}

Sturgeons (Acipenseridae) were once native in all major rivers of the Northern Hemisphere, but over the last 100 years, they have shown a drastic decline due to fishing, habitat destruction and hydro-construction as well as pollution. In general, sturgeons exhibit an unusual combination of behavior and life history characteristics, particularly their late onset of maturity, making them highly vulnerable to anthropogenic impacts (Rochard et al., 1990). Nowadays, sturgeons are among the most endangered fish species worldwide (IUCN, 2018) and several restoration programs have been implemented. Baltic sturgeon (Acipenser oxyrinchus) has been indigenous to the Baltic region for the last 8000 years, but is now considered extinct in German waters. Restocking programs have been established as a part of the ongoing recovery efforts to reintroduce Baltic sturgeons into their natural habitats and, thereby, initiate self-sustaining populations (Gessner et al. 2011).

However, there are major concerns regarding early life experiences in artificial environments that may not produce fish prepared to face life in the wild (Johnsson et al., 2014). Studies have shown that classical hatchery rearing negatively affects fish fitness and eventually the performance and survival of the fish upon release into the wild (Sulak et al., 2014). It is known that in the natural environment, sturgeons experience stimuli that shape and influence brain plasticity, cognition and behavioral phenotype. In contrast, modern hatchery practices, including high stocking densities, predictable feeding regimes and uniform stimulus-poor rearing conditions, can result in impaired cognition and behavioural responses in sturgeons reared in captivity, leading to reduced fitness and survival (Ebbesson and Braithwaite, 2012).

In contrast to mammals, fishes display remarkable plasticity in brain neurogenesis, which remains active throughout adult life. As a consequence, fish are sensitive too and respond to changes in both social and environmental conditions (Ebbesson and Braithwaite, 2012). In their natural habitats, most fishes experience environmental challenges and are able to adapt 
their physiology and behavior in order to cope more effectively. Much of this flexibility is supported and influenced by cognition and neural plasticity. Furthermore, current literature on fish cognition indicates that many fish species are capable of learning and integrating multiple pieces of information that require more complex processes than associative learning (Ebbesson and Braithwaite, 2012).

Neuroscientists have payed special attention to the molecular mechanisms of neural plasticity associated with memory. This work has resulted in markers related to neural plasticity. Recent studies have indicated that proneural gene neurogenic differentiation 1 factor (neurodl) is a reliable measure of neurogenesis in fish and a useful indicator of the neural plastic changes associated with memory and learning (Rossi et al.,2006; Grassie et al., 2013). Moreover, brain-derived neurotrophic factor (bdnf) has an important role in neural plasticity through sculpting and refinement of synapses and through promoting neurogenesis and cell survival (Castrén and Rantamäki, 2009). Though not specific to the brain, proliferating cell nuclear antigen (pcna) is a marker for cell proliferation in the respective organ (Leung et al., 2005). Taking into account the functions of the genes previously mentioned (neurodl, bdnf and pcna), they were of interest for this present study.In the wild, Baltic sturgeon is a benthic feeder which shows a digging behavior with help of the rostrum, preying on worms, shrimps and other invertebrates and making use of a powerful suction feeding mechanism (Carroll and Wainwright, 2003). Since most of their time is spent in waters with low visibility, feeding is performed by using a combination of olfactory, taste, tactile chemosensory cues and electroreceptors rather than vision (Mclean et al., 2013; Miller, 2004).The reduced importance of vision in feeding in sturgeons is supported by the observation that these fishes have relatively small eyes in relation to body size. In captivity, Baltic sturgeons are fed with artemia and thereafter with deep-frozen chironomids until they can be weaned on dry feed. 
98 Taking into account that efficient foraging behavior is a key determinant of juvenile

99 survival, the aim of this study was to determine whether natural foraging behaviour could be

100 improved in hatchery-reared Baltic sturgeon following a short training period. In addition, this

101 study also investigated whether this training resulted in positive changes in brain plasticity

102 and cognition. To that end, following training, brains were sampled for gene expression

103 analysis. 


\section{Materials and Methods}

\subsection{Experimental design}

The experiments were performed at the experimental facilities at the Leibniz Institute of Freshwater Ecology and Inland Fisheries (IGB, Berlin, Germany) using fish from the sturgeon stock kept at the IGB. The experiment was conducted successively with 4 trained and 4 nontrained one year old Baltic sturgeon (Acipenser oxyrinchus) (TL 19-25 cm, $34-37 \mathrm{~g}$ ) randomly distributed between 8 experimental raceway units $(2.40 \mathrm{~m} * 0.225 \mathrm{~m} * 0.1 \mathrm{~m})$ at a natural photoperiod and acclimatized for 7 days. Dissolved oxygen $(8.41-9.16 \mathrm{mg} / \mathrm{L})$, and temperature $\left(18-20{ }^{\circ} \mathrm{C}\right)$ were measured daily, nitrit-nitrogen $(0.002 \mathrm{mg} / \mathrm{L})$ and total ammonia (TAN, $0.021 \mathrm{mg} / \mathrm{L}$ ) every three days. Furthermore, 10 sturgeons were transferred to a constructed river stretch $(6 \mathrm{~m}$ length, $1 \mathrm{~m}$ width, $0.2 \mathrm{~m}$ water depth, supplied by a Pontec Pondomax Eco 8000 pump) simulating close to natural conditions. The pond group was reared in an outside river stretch in order to compare the results of the trained and non-trained experimental groups to a more naturalistic environment (positive control).

Three experimental groups were established: non-trained, trained and pond (8 fish per group). The 8 raceways were assigned to non-trained and trained experimental group. The trained group had a sandy bottom $(10 \mathrm{~cm}$ depth $)$ while for the non-trained group the four raceways were left bare $(10 \mathrm{~cm}$ depth).After a 7 day acclimatization period, during which the fish were fed chronomids, the training school started. The training was specifically designed to improve foraging behavior. Therefore, trained fish were fed chironomids hidden below a sand spot $(<10 \mathrm{~cm})$, while the fish in the remaining bare raceways received chironomids on the bare tank bottom (non-trained). Before feeding in the respective raceway, fish were isolated by introducing a wall which was removed after feed had been introduced in the remaining part of the raceway. In the pond group, chironomids were hidden in the sandy substrate. 
After 14 days, two sturgeon of each group were sampled for the gene expression, the remaining two fish were transferred to a raceway covered with sand (behavioral assessment). .

For the assessment, chironomids were hidden in the sand and time until successful foraging

was recorded for trained as well as for untrained fish $(n=8)$. If chronomids were not was repeated for seven consecutive days.

For the gene expression analysis, fish were euthanized with MS222 (300 ppm) followed by cutting through the spinal cord. Brains from 8 Baltic sturgeons per group (trained, nontrained, pond) were dissected and divided into three parts representing the three main brain regions (forebrain, midbrain and hindbrain). Samples were stored in RNA later at $-80{ }^{\circ} \mathrm{C}$ for later gene expression analysis.

All experiments were in compliance with EU Directive 2010/63/EU and approved by the national authorities (G0305/15, Landesamt für Gesundheit und Soziales, Berlin, Germany).

\subsection{Gene expression}

Total RNA was extracted with TRIzol as described by (Reiser et al., 2011), including a

DNase I digestion. Total RNA concentration and purity were determined in duplicates with a Nano chips with an Agilent 2100 Bioanalyzer. To eliminate potential DNA contamination, DNAse I digestion was performed in all samples prior to transcription. Next, mRNA was transcribed with MMLV Affinity reverse transcriptase (Agilent, 200 Units/ $\mu 1$ ) according to 
Species-specific primers targeting elongation factor $1 \alpha(e f 1 a)$, brain-derived neurotrophic

factor (bdnf), neurogenic differentiaton factor (neurodl) and proliferating cell nuclear antigen

(pcna) were designed using the sequence information available. Specificity of the assays was

confirmed by direct sequencing (SeqLab, Germany). Real-time PCR was carried out with

Mx3005p qPCR Cycler (Stratagene), monitoring specificity by melting curve analysis. Full

specifications of qPCR assays, including primer sequences are given in Table 1.

Briefly, $2 \mu \mathrm{L}$ of the diluted sample $(40 \mathrm{ng} / \mu \mathrm{L})$ were used as template in $20 \mu \mathrm{L}$ PCR mix

${ }^{\circ} \mathrm{C}$ for $3 \mathrm{~min}$, followed by 40 cycles of denaturation at $96{ }^{\circ} \mathrm{C}$ for $30 \mathrm{~s}$, primer annealing (for

Ta, see Table 1) for $30 \mathrm{~s}$ and elongation at $72{ }^{\circ} \mathrm{C}$ for $30 \mathrm{~s}$. PCR efficiencies were determined experimentally with a dilution series of a calibrator corresponding to $200 \mathrm{ng} / \mu \mathrm{l}$. PCR assays for all individual samples were run in duplicate. Expression of target genes were calculated by efficiencies and normalizing to elongation factor $1 \alpha$ (efla) as a housekeeping gene. Expression data are presented as fold increase of the respective control.

\subsection{Data analysis and statistical methods}

Data are presented as mean \pm standard deviation (SD). Prior to statistical analyses, all data were tested for normality of distribution using the Kolmogorov-Smirnov/ Shapiro Wilk test and for homogeneity using Levene test. Data on the behavior were analyzed using T-test. The level of significance used was $\mathrm{P} \leq 0.05$. All statistical analyses were performed with GraphPrism statistical program. 
176

177

\section{Results}

\subsection{Behavioral assessment}

In the behavioral assessment (Fig.1), significant differences were observed between nontrained and trained fish. While the time taken to initiate feeding successfully progressively decreased in both groups over the 7-day feeding study, this time was significantly less $(\mathrm{p}<0.05)$ in the trained compared to the non-trained fish at all time points (Fig. 1). On day 1, trained fish took $58 \pm 6$ min to successful foraging whereas none of the non-trained fish recovered the chironomids within $120 \mathrm{~min}$. After $7 \mathrm{~d}$, chironomids were recovered after $8 \pm 2$ min and $18 \pm 9 \mathrm{~min}$ in trained and non-trained fish, respectively.

\subsection{Brain plasticity and cognition}

Selected genes related to brain plasticity and cognition (neurodl, bdnf, pcna) were analyzed in all three brain areas of Baltic sturgeon. Regarding the forebrain region (Fig. 2), significant differences were observed in the expression of neurodl. In particular, there was an up-regulation in the trained and pond groups with respect to the non-trained group in Baltic sturgeon after $14 \mathrm{~d}$ of training (Fig 2A). Furthermore, pcna expression showed an upregulation in the pond group in comparison to both trained and non-trained groups in the forebrain of Baltic sturgeon (Fig. 2B). Similar results were observed in both midbrain and hindbrain region (Figs. 3B \& 4B) of Baltic sturgeon in which neurodl showed an upregulation in both the trained and pond groups compared to the non-trained group after $14 \mathrm{~d}$ of training. 
197

\section{Discussion}

Stocking still remains an important conservation tool to combat the continuing global decline in fish biodiversity (Pikitch et al., 2005). Hatcheries are a key element in the recovery plan for sturgeon and have been regarded as a temporary measure until more aggressive habitat restoration programs are established. In fact, hatcheries are currently the only viable option to increase sturgeon populations. Hatchery programs for sturgeon have demonstrated considerable success in collecting or developing brood-stock, spawning, and rearing juveniles. However, the success of sturgeon hatcheries for conservation will ultimately depend on how effectively the hatchery-reared sturgeon can adapt to the natural habitat following release (Brown and Day, 2002).

In general, when released directly into the rivers, the survival of hatchery reared juveniles from different fish species is only approximately 1-3\% after a few months due to a combination of predation, starvation and other factors (Brown and Day, 2002; Chebanov et al., 2011). Furthermore, it is widely accepted that post-release survival rates of hatcheryreared fish are lower compared to their wild conspecifics (Campton et al., 1991; Svasand and Kristiansen, 1990). Fisheries scientists are increasingly convinced that the uniform stimuluspoor environment experienced during hatchery rearing is one of the main contributing factors for this reduction in fitness and post-release survival (Ellis et al.,1997; Masuda and Tsukamoto, 1998). Thus, research to improve the post-release survival of hatchery-reared juveniles through behavioral performance is needed in order to continue successful recovery plans.

Suggested methods for improving the survival of hatchery fishes include supplementary feeding with live foods, the provision of under-water feeders, sub-aquatic structure, natural substratum, etc (Maynard and Flagg, 1994) In the wild, Baltic sturgeon is a benthic feeder which shows a digging behavior in order to find worms, shrimps and other 
222 invertebrates from the substrate (Miller, 2004). Like all fish behavior, foraging relies on

223 experience. The foraging skills of fishes become adjusted to ecological conditions through

224 learning (Hughes et al., 1992; Warburton, 2003). Fish are able to learn to recognize prey, how

225 to handle them and where they are likely to be located (Warburton, 2003). Results from the

226 behavioral assessment of this study suggest that a short training period can improve the

227 foraging ability of Baltic sturgeon by reducing the amount of time taken to successfully

228 forage. This significant improvement was seen in the first 7 days, which can be critical when

229 released into their natural habitat. This could be an important approach since when recaptured

230 after release into the wild, hatchery fishes are often found to have empty stomachs (O'Grady,

231 1983; Johnsen and Ugedal, 1989).

232

233

234

235

236

237

238

239

240

241

242

243

244

245

The understanding of fish cognition and the role played by different brain regions has improved significantly in recent years. Fish brain remains plastic throughout their entire life and continues to be sensitive to both social and environmental changes. Most fishes experience challenges in their environmental and are able to adjust and adapt their physiology and behavior to help them cope more effectively. Much of this flexibility is supported by cognition and neural plasticity. Neural plasticity allows for the development and function of cognitive processes (Ebbesson and Braithwaite, 2012; Knudsen, 2004), and thus has a large role in the adaptation to changing environments. Current literature on fish cognition indicates that many fish species are capable of learning and integrating multiple pieces of information that require more complex processes than just associative learning (Ebbesson and Braithwaite, 2012). The most important brain area for these complex neural processes in fish is the dorsolateral telencephalon (Dl) (Durán et al., 2010; Rodríguez et al., 2002; Wullimann and Mueller, 2004), and has been recognized as the functional homologue of the mammalian hippocampus (Mueller et al., 2011; Mueller and Wullimann, 2009). 
Studies using intermediate early genes (IEG) make possible to investigate which brain regions are activated during a particular cognitive process. In this study, three main genes were studied: neurogenic differentiation factor (neurod1), brain-derived neutrophic factor (bdnf) and proliferating cell nuclear antigen (pcna). Neurogenic differentiation factor (neurod1), is a member of a family of pro-neural genes, which is involved in the initiation and regulation of neural differentiation (Kiefer, 2005). Recent studies have shown that expression levels of neurodl mRNA is a reliable measure of neurogenesis in fish and a useful indicator of the neural plastic changes associated with memory and learning (Grassie et al., 2013; Salvanes et al., 2013). Brain-derived neurotrophic factor (bdnf) is the most abundantly expressed member of the nerve growth factor family, neurotrophins, and has an important role in neural plasticity through sculpting and refinement of synapses and through promoting neurogenesis and cell survival (Castrén and Rantamäki, 2009). It has recently been shown that environmental challenges alter $b d n f$ expression in the telencephalon of Atlantic salmon (Vindas et al., 2017). Regarding proliferating cell nuclear antigen ( $p c n a)$, it can be used as a marker for cell proliferation (Leung et al., 2005).

In this study, neurodl was up-regulated in all brain regions in both the trained-group and fish raised in the semi-natural pond, in comparison to the non-trained fish. This might be an indication of the stimulation of cognitive processes such as learning and memory as a result of the training method. Thus, it indicates that the fish from the trained group generally learnt to locate the prey. These results are in agreement with the results found in the behavioral assessment. 
271 period of training could potentially help Baltic sturgeon in their process of learning to

272 successfully forage, which could be a first approach to improve restocking practices. Since

273 rearing conditions are highly important in stocking for conservation, hatcheries should aim to

274 produce juveniles that are morphologically, genetically, behaviorally and physiologically

275 similar to the stock they pretend to enhance and recover. Furthermore, restoration programs

276 require a variety of information on sturgeon and thus, it is interesting to produce and keep up

277 to date extensive reviews of the literature. Further work is needed in order to determine the

278 survival of sturgeon reared under alternative hatchery-rearing practices taking into account

279 other key factors in sturgeon survival.

\section{Conclusion}

281 To our knowledge, this is the first study that looks into foraging training in Baltic sturgeon to

282 improve fitness for re-stocking purposes. We observed that both behavioural and

283 physiological parameters were improved by a short-term training period. This improvement

284 could significantly help Baltic sturgeon survive in the wild, since the highest percentage of 285 mortality happens during the first days post-release. 


\section{Declaration of Interest}

There are no conflicts to declare

Acknowledgments

The authors thank Eva Kreuz for her contribution in the laboratory. The study was

\section{Author contributions}

297 The experiment was conducted by C.E.S. The laboratory analysis was carried out by M.C.R.

298 M.C.R. wrote the first draft of the manuscript. S.V. supervised the project. The manuscript 299 was revised by all co-authors. 
301

302

303

304

305

306

307

308

309

310

311

312

313

314

315

316

317

318

319

\section{References}

Brown, C., Day, R.L., 2002. The future of stock enhancements: Lessons for hatchery practice from conservation biology. Fish Fish. 3, 79-94. https://doi.org/10.1046/j.14672979.2002.00077.

Campton, D.E., Allendorf, F.W., Behnke, R.J., Utter, F.M., Chilcote, M.W., Leider, S.A., 1991. Reproductive Success of Hatchery and Wild Steelhead. Trans. Am. Fish. Soc. 120, 816-827. https://doi.org/10.1577/1548-8659(1991)120.

Carroll, A.M., Wainwright, P.C., 2003. Functional Morphology of Prey Capture in the Sturgeon, Scaphirhynchus albus. J. Morphol. 284, 270284.https://doi.org/10.1002/jmor.10095.

Castrén, E., Rantamäki, T., 2009. The Role of BDNF and Its Receptors in Depression and Antidepressant Drug Action $\square$ : Reactivation of Developmental Plasticity. Dev. Neurobiol. 70, 289-297. https://doi.org/10.1002/dneu.20758.

Chebanov, M., Rosenthal, H., Gessner, J., Van Anrooy, R., Doukakis, P., Pourkazemi, M., Williot, P., 2011. Sturgeon hatchery practices and management for release: Guidelines. FAO Fish. Aquac. 110.

Durán, E., Ocaña, F.M., Broglio, C., Rodríguez, F., Salas, C., 2010. Lateral but not medial telencephalic pallium ablation impairs the use of goldfish spatial allocentric strategies in a "hole-board" task. Behav. Brain Res. 214, 480487.https://doi.org/10.1016/j.bbr.2010.06.010.

Ebbesson, L.O.E., Braithwaite, V.A., 2012. Environmental effects on fish neural plasticity and cognition. J. Fish Biol. 81, 2151-2174. https://doi.org/10.1111/j.10958649.2012.03486.

Ellis, T., Howell, B.R., Hayes, J., 1997. Morphological differences between wild and hatchery-reared turbot. J. Fish Biol. 50, 1124-1128.

Gessner, J., Arndt, G.M., Fredrich, F., Ludwig, A., Kirschbaum, F., Bartel, R., von Nordheim, H., 2011. Remediation of Atlantic Sturgeon Acipenser oxyrinchus in the Oder River: Background and First Results. pp 539-559. In Willio, P. et al (eds), Biology and Conservation of the European Sturgeon Acipenser sturio L. 1758, DOI 10.1007/978-3642-20611-5_41, Springer-Verlag Berlin Heidelberg 2011. 
Grassie, C., Braithwaite, V.A., Nilsson, J., Nilsen, T.O., Teien, H.C., Handeland, S.O., Stefansson, S.O., Tronci, V., Gorissen, M., Flik, G., Ebbesson, L.O.E., 2013. Aluminum exposure impacts brain plasticity and behavior in Atlantic salmon (Salmo salar). J. Exp. Biol. 216, 3148-3155. https://doi.org/10.1242/jeb.083550.

Hughes, R.N., Kaiser, M.J., Mackney, P.A., Warburton, K., 1992. Optimizing foraging behaviour through learning. J. Fish Biol. 41, 77-91. https://doi.org/10.1111/j.10958649.1992.tb03870.

IUCN, 2018. The IUCN Red List of Threatened Species. Version 2018-1.

Johnsen, B.O., Ugedal, O., 1989. Feeding by hatchery-reared brown trout, Salmo trutta L . released in lakes. Aquac. Fish. Manag. 20, 97-104.

Johnsson, J.I., Brockmark, S., Näslund, J., 2014. Environmental effects on behavioural development consequences for fitness of captive-reared fishes in the wild. J. Fish Biol. 85, 1946-1971. https://doi.org/10.1111/jfb.12547.

Kiefer, J.C., 2005. Proneural factors and neurogenesis. Dev. Dyn. 234, 808-813. https://doi.org/10.1002/dvdy.20522.

Knudsen, E.I., 2004. Sensitive periods in the development of the brain and behavior. J Cogn Neurosci 16, 1412-1425. https://doi.org/10.1162/0898929042304796.

Leung, A.Y.H., Leung, J.C.K., Chan, L.Y.Y., Ma, E.S.K., Kwan, T.T.F., Lai, K.N., Meng, A., Liang, R., 2005. Proliferating cell nuclear antigen (PCNA) as a proliferative marker during embryonic and adult zebrafish hematopoiesis. Histochem. Cell Biol. 124, 105111. https://doi.org/10.1007/s00418-005-0003-2.

Masuda, R., Tsukamoto, K., 1998. Stock enhacement in Japan: Review and Perspective.Bull. Mar. Sci. 62, 337-358.

Maynard, D.J., Flagg, T. A., 1994. A review of seminatural culture strategies for enhancing the postrelease survival of anadromous salmonids. Am. Fish. Soc. 1-34.

Mclean,M.F., Dadswell, M.J., Stokesbury, M.J.W., 2013. Feeding ecology of Atlantic sturgeon, Acipenser oxyrinchus oxyrinchus Mitchill , 1815 on the infauna of intertidal mudflats of Minas Basin, Bay of Fundy. J. Appl. Icththyol. 29, 503-509. https://doi.org/10.1111/jai.12175. 
Miller, M.J., 2004. the Ecology and Functional Morphology of Feeding of North American Sturgeon and Paddlefish. Ocean Res. 87-102. https://doi.org/10.1007/1-4020-2833-4_5.

Mueller, T., Dong, Z., Berberoglu, M., Guo, S., 2011. The dorsal pallium in zebrafish, Danio rerio (Cyprinidae, Teleostei). Brain Res. 95-105. https://doi.org/10.1016/j.brainres.2010.12.089.

Mueller, T., Wullimann, M.F., 2009. An evolutionary interpretation of teleostean forebrain anatomy. Brain. Behav. Evol. 74, 30-42. https://doi.org/10.1159/000229011.

O'Grady, M.F., 1983. Observations on the dietary habits of wild and stocked brown trout, Salmo trutta L ., in Irish lakes. J. Fish Biol. 22, 593-601.

Pfaffl, M.W., 2001. A new mathematical model for relative quantification in real-time RTPCR. Nucleic Acids Res. 29, 45.

Pikitch, E.K., Doukakis, P., Lauck, L., Chakrabarty, P., Erickson, D.L., 2005. Status, trends and management of sturgeon and paddle sh sheries. Wildl. Conserv. 233-265. https://doi.org/10.1111/j.1467-2979.2005.00190.

Reiser, S., Wuertz, S., Schroeder, J.P., Kloas, W., Hanel, R., 2011. Risks of seawater ozonation in recirculation aquaculture - Effects of oxidative stress on animal welfare of juvenile turbot (Psetta maxima, L.). Aquat. Toxicol. 105, 508-517. https://doi.org/10.1016/j.aquatox.2011.08.004.

Rochard, E., Castelnaud, G., Lepage, M., 1990. Sturgeons (Pisces: Acipenseridae); threats and prospects. J. Fish Biol. 37, 123-132. https://doi.org/10.1111/j.1095-8649.1990.tb05028.

Rodríguez, F., López, J.C., Vargas, J.P., Gómez, Y., Broglio, C., Salas, C., 2002. Conservation of spatial memory function in the pallial forebrain of reptiles and rayfinned fishes. J. Neurosci. 22, 2894-903. https://doi.org/20026211.

Rossi, C., Angelucci, A., Constantin, L., Braschi, C., Mazzantini, M., Babbini, F., Fabbri, M.E., Tessarollo, L., Maffei, L., Berardi, N., Caleo., M., 2006. Brain-derived naurotrophic factor (BDNF) is required for the enhancement of hippocampal neurogenesis following environmental enrichments. Eur. J. Neurosci. 24, 1850-1856.

Salvanes, A.G.V., Moberg, O., Ebbesson, L.O.E., Nilsen, T.O., Jensen, K.H., Braithwaite, 
5

06

V.A., 2013. Environmental enrichment promotes neural plasticity and cognitive ability in fish Environmental enrichment promotes neural plasticity and cognitive ability in fish. Proc. R. Soc. B 280. https://doi.org/10.1098/rspb.2013.1331.

Sulak, B.K.J., Randall, M.T., Clugston, J.P., 2014. Survival of hatchery Gulf sturgeon ( Acipenser oxyrinchus desotoi Mitchill , 1815 ) in the Suwannee River, Florida $\square$ : A 19year evaluation 30, 1428-1440. https://doi.org/10.1111/jai.12607.

Svasand, T., Kristiansen, T.S., 1990. Enhancement studies of coastal cod in western Norway . Part IV . Mortality of reared cod after release 30-39.

Vindas, M.A., Gorissen, M., Höglund, E., Flik, G., Tronci, V., Damsgård, B., Thörnqvist, P.O., Nilsen, T.O., Winberg, S., Øverli, Ø., Ebbesson, L.O.E., 2017. How do individuals cope with stress? Behavioural, physiological and neuronal differences between proactive and reactive coping styles in fish. J. Exp. Biol. 220, 1524-1532. https://doi.org/10.1242/jeb.153213.

Warburton, K., 2003. Learning of foraging skills by fish. Fish Fish. 4, 203-215.

Wullimann, M.F., Mueller, T., 2004. Teleostean and Mammalian Forebrains Contrasted $\square$ : Evidence from Genes to 162, 143-162. https://doi.org/10.1002/cne.20183. 


\section{Figure legends}

409 Figure 1. Behavioural assessment. Time taken by Baltic sturgeon (A. oxyrinchus) of the non-

410 trained, trained and pond group to successfully forage. Significant differences are indicated by

411 asterisk (Tukey's, $\mathrm{P}<0.05, \mathrm{n}=8$ )

412 Figure 2. Gene expression, determined by qPCR, in the forebrain of Baltic sturgeon (A. 413 oxyrinchus) of the non-trained, trained and pond group after 14 days of training. Data are 414 expressed as fold relative. Groups with different subscripts are significantly different $(\mathrm{P}<$ $4150.05, \mathrm{n}=8$ ). Statistic test used (Dunn's or Tukey's) is indicated below the respective graph.

416 Figure 3. Gene expression, determined by qPCR, in the midbrain of Baltic sturgeon $(A$. 417 oxyrinchus) of the non-trained, trained and pond group after 14 days of training. Data are 418 expressed as fold relative. Groups with different subscripts are significantly different ( $\mathrm{P}<$ $4190.05, \mathrm{n}=8$ ). Statistic test used (Dunn's or Tukey's) is indicated below the respective graph.

420 Figure 4. Gene expression, determined by qPCR, in the hindbrain of Baltic sturgeon $(A$. oxyrinchus) of the non-trained, trained and pond group after 14 days of training. Data are expressed as fold relative. Groups with different subscripts are significantly different $(\mathrm{P}<$ $0.05, \mathrm{n}=8$ ). Statistic test used (Dunn's or Tukey's) is indicated below the respective graph.

\section{Tables}

425

Table 1. Specifications of qPCR assays including primer sequences, annealing temperature (Ta), amplicon length [bp], PCR efficiency (Eff) and NCBI accession number of the respective housekeeping (ef) and target genes: ef- elongation factor $1 \mathrm{a}$, neurod1- neurogenic differentiation factor, bdnf - brain-derived neurotrophic factor, pcna- proliferating cell nuclear antigen-

\begin{tabular}{|c|c|c|c|c|c|c|}
\hline gene & primer & 5'-3' sequence & $\mathrm{Ta}\left[{ }^{\circ} \mathrm{C}\right]$ & $\begin{array}{c}\text { length } \\
\text { [bp] }\end{array}$ & Eff. $^{\prime}[\%]$ & GeneBank \# \\
\hline \multirow[t]{2}{*}{$\overline{e f a}$} & $f$ & TCAgggAgAAgATTgACCgT & 65 & 239 & 97 & 2160436 \\
\hline & r & AgACTTggTgACTTTgCCTg & & & & \\
\hline \multirow[t]{2}{*}{ neuroD } & $f$ & TATCATTCCCCTggTCTgCC & 65 & 175 & 98 & 2160451 \\
\hline & r & CATTAACgCTCAgTggTggg & & & & \\
\hline pcna & $f$ & gAAgAAggTTTTggAggCg & 65 & 187 & 92.5 & 2160452 \\
\hline
\end{tabular}


bioRxiv preprint doi: https://doi.org/10.1101/483651; this version posted November 30,2018 . The copyright holder for this preprint (which was not certified by peer review) is the author/funder, who has granted bioRxiv a license to display the preprint in perpetuity. It is made available under aCC-BY-NC-ND 4.0 International license.

\begin{tabular}{lllllll}
\multicolumn{1}{c}{} & $r$ & CCTgCTCAgATTgACCCC & & & & \\
bdnf & $f$ & gACggCCgTAgACAAgAAgA & 65 & 188 & 84.5 & 2160439 \\
& $r$ & TggTCCgACACTgTgAATTg & & & & \\
\hline
\end{tabular}

${ }^{1}$ Efficiency was determined from serial dilution series

432 


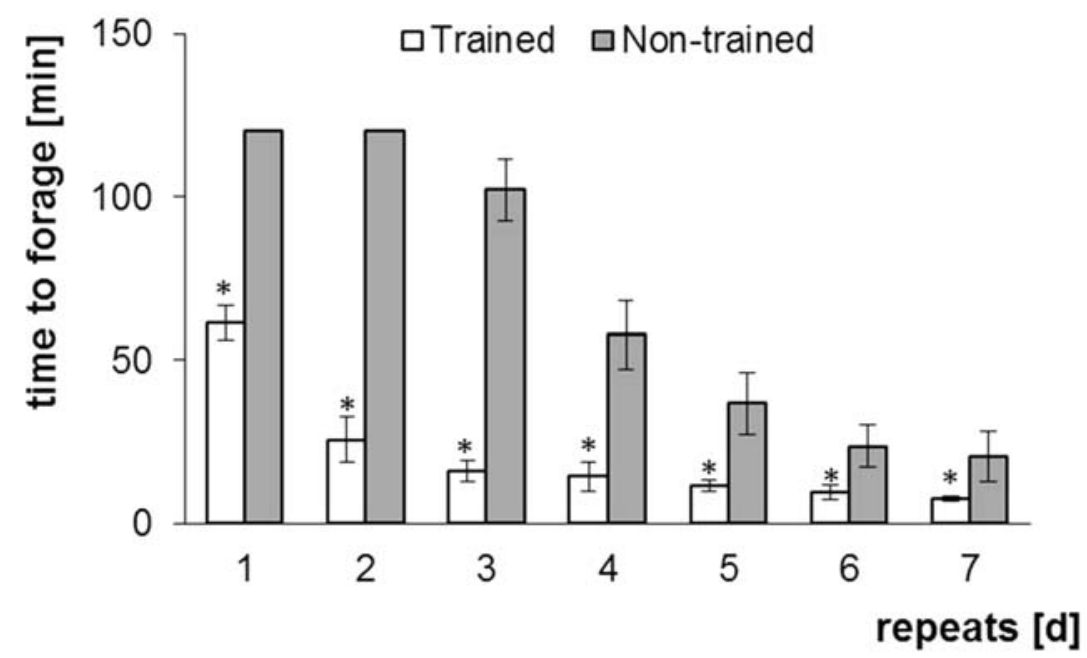

Figure 1. Behavioural assessment. Time taken by Baltic sturgeon (A. oxyrinchus) of the nontrained, trained and pond group to successfully forage. Significant differences are indicated by asterisk (Tukey's, $\mathrm{P}<0.05, \mathrm{n}=8$ ) 

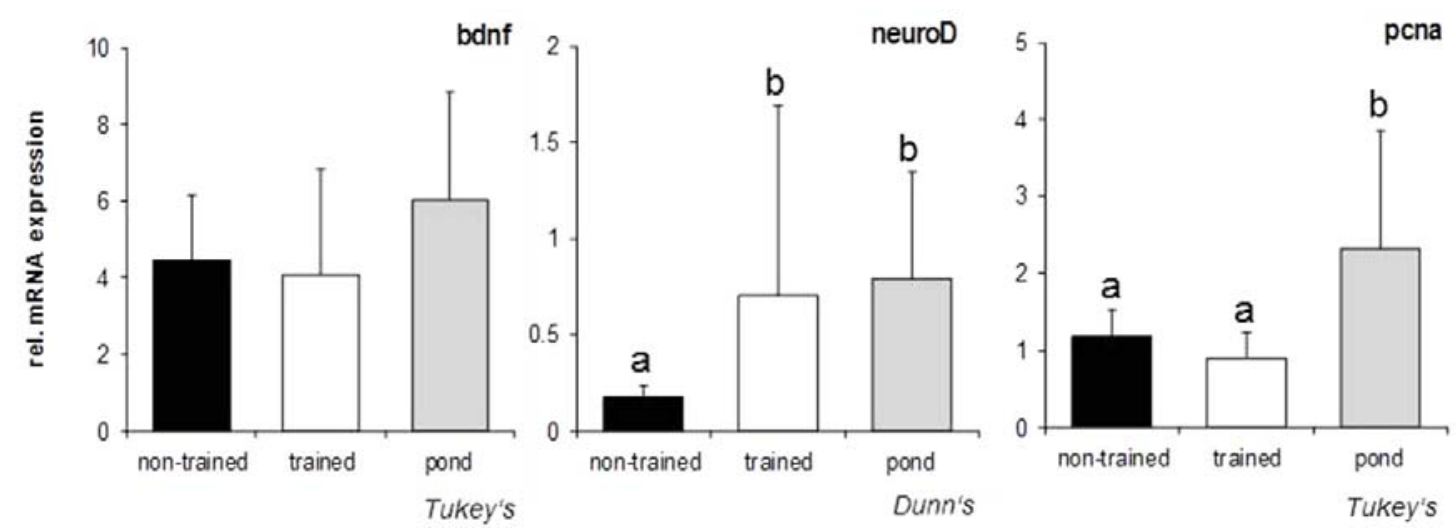

Figure 2. Gene expression, determined by qPCR, in the forebrain of Baltic sturgeon ( $A$. oxyrinchus) of the non-trained, trained and pond group after 14 days of training. Data are expressed as fold relative. Groups with different subscripts are significantly different $(\mathrm{P}<$ $0.05, \mathrm{n}=8$ ). Statistic test used (Dunn's or Tukey's) is indicated below the respective graph. 

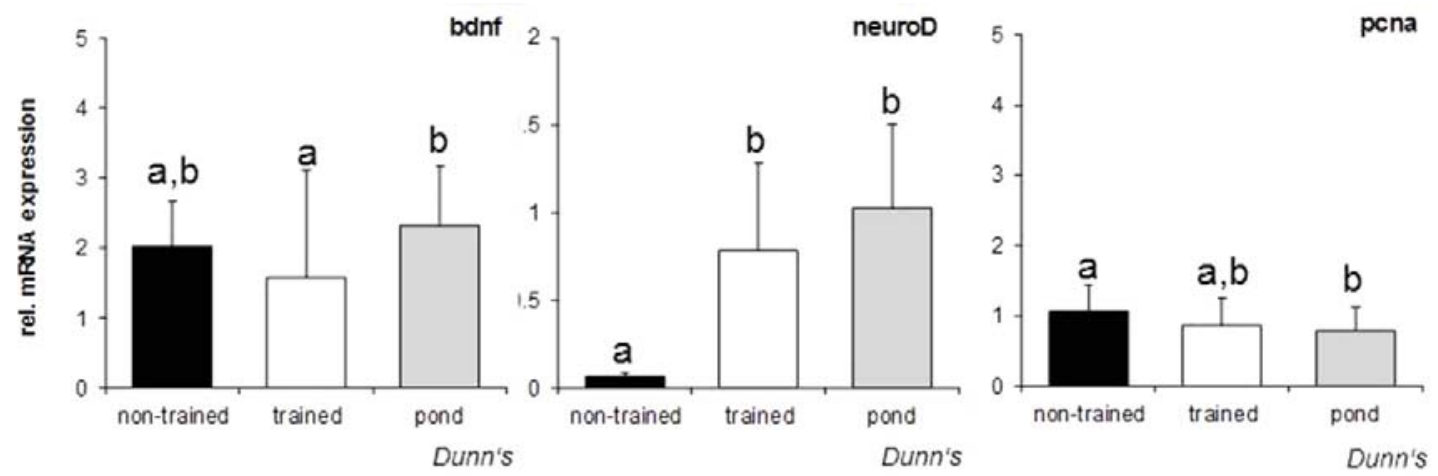

Figure 3. Gene expression, determined by $\mathrm{qPCR}$, in the midbrain of Baltic sturgeon $(A$. oxyrinchus) of the non-trained, trained and pond group after 14 days of training. Data are expressed as fold relative. Groups with different subscripts are significantly different $(\mathrm{P}<$ $0.05, \mathrm{n}=8$ ). Statistic test used (Dunn's or Tukey's) is indicated below the respective graph. 


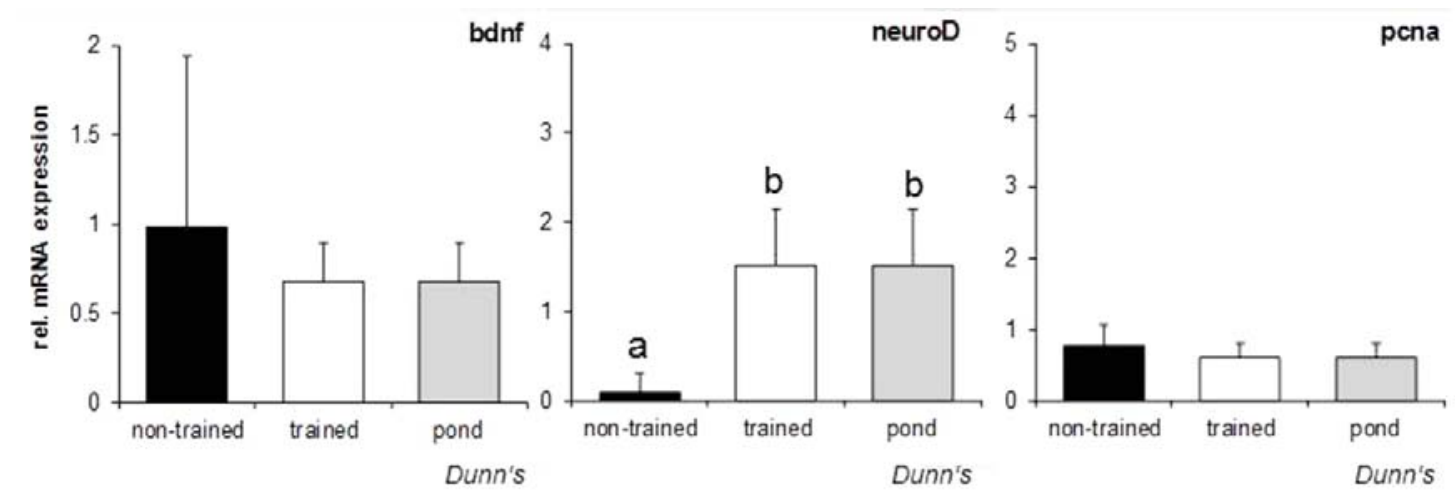

Figure 4. Gene expression, determined by qPCR, in the hindbrain of Baltic sturgeon $(A$. oxyrinchus) of the non-trained, trained and pond group after 14 days of training. Data are expressed as fold relative. Groups with different subscripts are significantly different $(\mathrm{P}<$ $0.05, \mathrm{n}=8$ ). Statistic test used (Dunn's or Tukey's) is indicated below the respective graph. 